\title{
0 rendimento escolar e o esporte na vida de alunos/atletas ${ }^{1}$
}

\section{School income and sport in the life of students/athletes \\ Desempeño escolar y deporte en la vida de estudiantes/ atletas}

\author{
iD (9) Deyvid Tenner de Souza Rizzo \\ Universidade Federal do Mato Grosso do Sul (UFMS), Corumbá-MS, Brasil \\ E-mail: deyvidrizzo1@gmail.com \\ iD (9) Rogério Zaim-de-Melo \\ Universidade Federal do Mato Grosso do Sul (UFMS), Corumbá, MS, Brasil \\ E-mail: rogeriozmelo@gmail.com \\ iD Alcides José Scaglia \\ Faculdade de Ciências Aplicadas - UNICAMP, Campus Limeira, São Paulo - Brasil \\ E-mail: alcides.scaglia@fca.unicamp.br \\ iD (9) Marcelo José Taques \\ Universidade Federal da Grande Dourados (UFGD), Dourados-MS, Brasil. \\ E-mail: marcelotaques@ufgd.edu.br \\ iD Ana Paula Moreira de Sousa \\ Doutoranda em Educação (Universidade Federal da Grande Dourados), Dourados, \\ Mato Grosso do Sul, Brasil. \\ E-mail: profap.educa@gmail.co
}

Resumo: O estudo objetiva analisar a influência do esporte no rendimento escolar de alunos atletas dos Jogos da Juventude de Mato Grosso do Sul a partir da percepção de treinadores. É uma pesquisa quali-quantitativa. Para tanto, utilizou-se do software IRAMUTEQ. Os resultados indicam que a falta de apoio dos professores das escolas, com programas flexíveis, dificulta o bom desempenho escolar dos alunos atletas. Não

10 presente trabalho não contou com apoio financeiro de nenhuma natureza para sua realização. 
foram encontrados indícios significantes de que o desempenho escolar seja prejudicado pela rotina dos treinos e competições. Consideramos que um trabalho interdisciplinar entre treinadores, professores e gestores escolares pode favorecer o planejamento de ações que promovam mudanças positivas para o desempenho escolar e para programas de treinamento esportivo.

Palavras-chave: Educação. Desempenho escolar. Esporte.

Abstract: The study aims to analyze the influence of sport on the academic performance of student athletes of the Youth Games of Mato Grosso do Sul from the perception of coaches. It is a qualitative and quantitative research and the software IRAMUTEQ was used. The results indicate that the lack of support from school teachers, with flexible programs hinders the good school performance of student athletes. No significant evidence was found that school performance is hindered by the training and competition routine. We consider that an interdisciplinary work between coaches, teachers and school managers can favor the planning of actions that promote positive changes for school performance and for sports training programs.

Keywords: Physical education. School income. Sport.

Resumen: El estudio tiene como objetivo analizar la influencia del deporte en el rendimiento escolar de los estudiantes atletas de los Juegos Juveniles de Mato Grosso do Sul desde la percepción de los entrenadores. Es una investigación cualitativa y cuantitativa y se utilizó el software IRAMUTEQ. Los resultados indican que la falta de apoyo de los maestros de escuela, con programas flexibles, dificulta el buen desempeño escolar de los estudiantes atletas. No se encontró evidencia significativa de que el rendimiento escolar se vea obstaculizado por la rutina de entrenamiento y competencia. Consideramos que un trabajo interdisciplinario entre entrenadores, maestros y administradores escolares puede favorecer la planificación de acciones que promuevan cambios positivos para el rendimiento escolar y para los programas de entrenamiento deportivo.

Palavras-clave: Educación Física. Rendimiento escolar. Deporte.

Submetido em: 30-07-2020

Aceito em: 20-10-2020 


\section{Introdução}

O cerne desta pesquisa centra-se na percepção dos treinadores que atuam na escola com a função de treinar os alunos-atletas participantes dos Jogos da Juventude de Mato Grosso do Sul (JOJUMS). A influência do esporte entre alunos-atletas, na ótica de treinadores, foi objeto de estudo de vários pesquisadores (LUGUETTI et al., 2015; RODRIGUES; SALDANHA, 2016). O ponto de vista, a formação, as experiências (LUGUETTI et al., 2013), a motivação autodeterminada (BALAGUER et al., 2015) dos treinadores são preocupações emergentes no âmbito científico, assim como os impactos da relação entre o treinador e o atleta em período de escolarização (VIEIRA et al., 2015).

A partir disso, questionamos: o rendimento escolar de alunos-atletas é beneficiado ou prejudicado pela prática esportiva? A presente pesquisa se propõe a contribuir com a reflexão pautada em evidências sobre esse tema, mais especificamente investigar a influência do esporte no rendimento escolar de jovens atletas a partir da percepção dos treinadores.

A partir desse contexto, o rendimento escolar é analisado de diferentes formas, as quais incluem notas escolares e distintos instrumentos (MAHENDRA; MARIN, 2020). Nesta investigação, optou-se por utilizar a reprovação escolar e as notas como critério avaliativo para caracterizar o conceito de rendimento escolar.

Nesse cenário, surge o esporte como um dos maiores, se não o maior, fenômenos socioculturais do século XX (OLIVEIRA, 2010, MOREIRA; NISTA-PICCOLO). Atualmente, a prática esportiva é investigada num universo composto por diversos profissionais, além da Educação Física e da ciência do desporto, pois "o fazer didático da Educação Física" (SILVA; RUFINO; DARIDO, 2013, p. 1) se mostra relevante no currículo cultural da Educação Física (NETA et al., 2020), destacando-se a pedagogia que "contribuiu significativamente para intervenções sobre o processo, de ensino e aprendizagem por meio da disciplina de pedagogia do esporte", com ênfase 
na pedagogia não linear como estrutura pedagógica (MACHADO et al., 2019).

O final da década 1990-2000 e início do século XXI se configuram como um período de muitos embates acadêmicos envolvendo a prática esportiva no contexto escolar, tanto no contraturno quanto nas aulas propriamente ditas, com aproximações e distanciamentos em suas bases epistemológicas. Nesse contexto, muitos estudos evidenciaram a possibilidade/necessidade de uma emancipação entre o esporte e a escola (BRACHT, 2001; GAYA, 2000; LOVISOLO, 2001; TAFFAREL, 2000; VAZ, 2001), sendo crucial sustentar e construir metodologias inovadoras em pedagogia do esporte (RIZZO, 2017; SCAGLIA et al., 2013).

Independente da relação harmoniosa/conflituosa entre esporte e escola, o desempenho escolar, muitas vezes usado como moeda de troca entre responsáveis e treinadores para a permanência do aluno/atleta na equipe, é um indicador que tem como objetivo avaliar e mensurar a aprendizagem dos alunos. Nesse contexto, é possível afirmar que a prática esportiva é uma ação responsável por influenciar diretamente os índices de desempenho escolar dos alunos que praticam esportes de maneira sistematizada?

O desempenho escolar é considerado fundamental para o futuro sucesso profissional e social (OLIVA et al., 2019), sendo apontado como importante preditor social e ocupacional na vida adulta (SERBIN; STACK; KINGDON, 2013; WINDING et al., 2013). As estratégias para instigar os alunos a debates em temas específicos da Educação Física escolar aparecem como recursos importantes nas ações pedagógicas do professor (TORRES et al., 2016).

Não obstante, podemos conjecturar que o processo educacional é complexo, determinado por múltiplos fatores, como a condição socioeconômica, a família, as relações na escola etc. (BREKKE, 2015; MARCHESI; GIL, 2004; WINDING; ANDERSEN, 2015). O desempenho de um aluno na escola está relacionado ao conhecimento obtido acerca dos componentes curriculares, tendo como indicadores as horas de estudo, as avaliações, notas etc. Contudo, 
esse desempenho não é linear, proporcional a determinadas horas de estudos, por exemplo, vários motivos correlacionam e influenciam diretamente a aprendizagem do estudante, ocasionando em sucesso ou fracasso, por isso, o rendimento escolar é uma preocupação no âmbito educacional e social (FORMIGA, 2004).

A carreira de um atleta, independentemente da idade, é composta por treinamentos, competições, viagens, tratamentos médicos e fisioterápicos que despertam muitas dúvidas no que concerne aos benefícios dessas práticas, principalmente no que tange à formação escolar. Logo, é imprescindível olhar para o treinamento esportivo realizado por crianças e jovens com a pretensão de compreender se eles estão negligenciando outros aspectos fundamentais das suas vidas por causa da prática esportiva, dentre eles, o aprendizado escolar, pois, alunos com "indicadores de apoio social e da comunidade indicam melhor desempenho escolar" e melhoram a satisfação com a vida (ACHKAR et al., 2019).

Athayde et al. (2019) identificaram a necessidade de se incrementar continuamente os mecanismos de verificação de desempenho escolar no intuito de entendê-los de acordo com as individualidades de cada sujeito. Sendo assim, compreender a importância da relação do esporte com o desempenho escolar dos alunos-atletas torna-se fundamental, pois muitos deles têm a prática esportiva como uma atividade contínua em seu cotidiano.

O fato de existirem estudos que indicam que praticantes de esporte no contraturno escolar possuem melhores níveis de percepção de qualidade de vida do que os que não praticam nenhuma prática esportiva (PACÍFICO et al., 2018), torna ainda mais relevante a investigação do problema apresentado.

Considerando, ainda, que as habilidades motoras dos alunos-atletas podem ser desenvolvidas em diferentes modalidades esportivas (TEIXEIRA et al., 2016), nesse contexto, pesquisadores indicam que as habilidades motoras são ampliadas durante a idade escolar, com possível relação entre desempenho motor e aprendizagem escolar (VILELLA-CORTEZ et al., 2019). 
O efeito de programas esportivos sistematizados na vida de alunos-atletas é motivo de diversas pesquisas. Silva et al. (2019) estudaram o efeito de um programa estruturado de iniciação a lutas com atenção no desempenho escolar de crianças do ensino fundamental. Pelegrini et al. (2011) analisaram níveis de aptidão física relacionada à saúde de escolares brasileiros no contexto do projeto esporte Brasil. Silva et al. (2017) investigaram o uso de substâncias ilícitas entre jovens estudantes brasileiros nos Jogos Escolares da Juventude.

Nessa direção, um estudo aponta melhorias no desempenho escolar em crianças que tiveram uma média de 150 minutos por semana de atividades que incluem esportes (TELFORD et al., 2011). Por essa razão, os treinadores têm a responsabilidade de promover atividades e estilo de vida saudável em crianças e adolescentes (SIERRA-DÍAZ et al., 2019), especialmente sobre a relação entre o rendimento escolar e as atividades esportivas organizadas que ocorrem na vida dos jovens (CENTERS FOR DISEASE CONTROL AND PREVENTION, 2010).

Dentro desse contexto, de que forma o rendimento escolar dos alunos-atletas é influenciado pela prática de esportes? A partir desse questionamento, objetiva-se analisar a influência do esporte no rendimento escolar de alunos-atletas participantes dos JOJUMS a partir da percepção de treinadores.

\section{O caminho percorrido}

Para atingir os objetivos da pesquisa, aprovada pelo Comitê de Ética em Pesquisa da Universidade Federal de Mato Grosso do Sul - UFMS (CAAE: 11923119.4.0000.0021/ Número do parecer: 3.354.431), realizou-se um estudo de natureza quali-quantitativa de cunho exploratório. A pesquisa exploratória é "um estudo do status" (THOMAS; NELSON; SILVERMAN, 2012, p. 293), neste caso, o status da influência do esporte sobre o rendimento escolar de alunos-atletas dos JOJUMS a partir da percepção dos treinadores. 
Optou-se por uma abordagem de natureza quali-quantitativa, pois, de acordo com Limena e Rodrigues (2006), essa tipologia é a mais indicada para investigações em que apenas os procedimentos estatísticos não alcançam ou representam em virtude de sua complexidade. Entre esses problemas, destacam-se aspectos sociais, psicológicos, opiniões, comportamentos, atitudes de indivíduos ou de grupos. Considerando, ainda, que "nada pode ser intelectualmente um problema, se não tiver sido, em primeiro lugar, um problema da vida prática" (MINAYO, 2004, p. 35).

Os JOJUMS são organizados pela Fundação de Desporto e Lazer de Mato Grosso do Sul (FUNDESPORTE). A organização desse evento é de uma entidade responsável pela gestão das políticas públicas de esporte e lazer do Estado de MS, cujo objetivo é fomentar, promover, orientar e apoiar a prática e difusão das manifestações esportivas e do lazer, em colaboração com órgãos e entidades públicas ou privadas. As atividades são financiadas com recursos oriundos do Fundo de Investimento Esportivo - FIE e recursos transferidos da União da Lei Pelé. Os jogos são realizados em diferentes períodos e em várias cidades no MS, com diversas práticas esportivas contempladas nesse contexto (judô, badminton, tênis de mesa, vôlei de praia, xadrez, ginástica rítmica, ciclismo futsal, basquete, handebol e voleibol), e as equipes campeãs classificam-se para as Olimpíadas Escolares Brasileiras, para jovens de 15 a 17 anos. A culminância do evento lócus da pesquisa foi de 13 a 15 de setembro de 2019, na cidade de Corumbá-MS, com ênfase na natação e no atletismo.

O levantamento dos dados foi realizado no dia agendado para realização da reunião técnica das equipes, quando os pesquisadores entregaram os 39 questionários, divididos entre todos os treinadores de cada delegação, totalizando 39 treinadores. Foi acordado entre a comissão organizadora dos JOJUMS que os treinadores responderiam os questionários nas hospedagens das equipes e, posteriormente, os pesquisadores recolheriam os questionários preenchidos numa data e horário pré-agendado. Nesse viés, houve um retorno de 10 questionários preenchidos corretamente pelos 
treinadores. Foram desconsiderados questionários preenchidos parcialmente ou entregues em branco. Ressaltamos que alguns treinadores também não deram uma devolutiva.

A amostra foi constituída por 10 treinadores ( 6 homens e 4 mulheres) entre 24 e 55 anos de idade ( 5 treinadores na modalidade de atletismo e 5 na natação), com experiência na profissão de treinador que variava entre 4 meses e 38 anos. Os treinadores que responderam ao questionário concentram-se na região Sul de MS e na região do Pantanal sul-mato-grossense. Como critério de inclusão, eles deveriam estar com equipes inscritas nos JOJUMS e com registro regular no Conselho Regional de Educação Física (CREF). Todos os sujeitos enquadrados nos critérios supracitados consentiram em participar da pesquisa, resultando em amostra composta por $100 \%$ dos indivíduos da população alvo. A escolha dos participantes foi intencional (amostragem não probabilística), considerando, para tanto, os objetivos da investigação.

O instrumento de coleta de dados utilizado no presente estudo foi validado a partir da avaliação de três especialistas (doutores), pensado para obter informações que caracterizam a influência do esporte no rendimento escolar a partir da percepção dos treinadores. A versão final do questionário foi composta de 11 questões (abertas, fechadas, múltipla escolha/escala de likert).

Para a análise das respostas das questões abertas, foi utilizado o software Analyses Multidimensionnelles de Textes et de Questionnaires (IRAMUTEQ), com análises textuais do tipo: pesquisa de especificidades de grupos; análises de similitude e nuvem de palavras. Essas ferramentas ofereceram a oportunidade de analisar diferentes grupos de palavras que foram utilizadas pelos treinadores no questionário. Com isso, foi possível categorizar as palavras em classes e, consequentemente, visualizar aproximações e distanciamentos em seus discursos. Desenvolvido por Ratinaud e Marchand (2012), o IRAMUTEQ é um programa informático que se ancora no software R e permite diferentes formas de análises estatísticas sobre corpus textuais e de indivíduos por palavras. Desenvolvido, inicialmente, em língua francesa, esse programa co- 
O rendimento escolar e o esporte na vida de alunos/atletas

Deyvid Tenner de Souza Rizzo • Rogério Zaim-de-Melo • Alcides José Scaglia • Marcelo José Taques • Ana Paula Moreira de Sousa

meçou a ser utilizado na língua portuguesa em 2013 (CAMARGO; JUSTO, 2013).

\section{Resultados}

Segundo os treinadores, a carga horária de treinamento dos alunos-atletas é de 4 a 20 horas semanais. Os resultados indicam que $80 \%$ dos treinadores consideram que o treinamento esportivo não atrapalha o desempenho escolar dos atletas. Apenas um treinador afirmou que é "difícil manter desempenho escolar com desempenho esportivo. Alguém sai prejudicado" (TREINADOR 9).

Contudo, unanimemente, todos recomendariam treinamentos para crianças a partir da primeira infância ( 6 anos de idade), com o intuito de auxiliar no desempenho escolar. O gráfico a seguir aponta como os treinadores acompanham o desempenho escolar dos atletas.

Gráfico 1. Acompanhamento o desempenho escolar

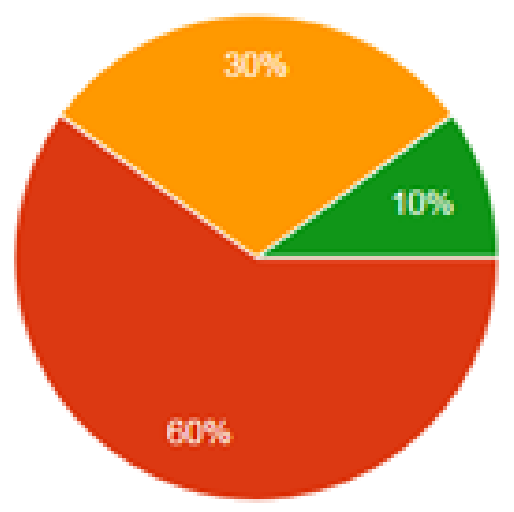

Não acompanho o desempenho escolar, meu foco é a prática esportiva.

Solicito apresentaçăo de notas bimestrais

Acompanhamento em conjunto com os pais

Visitas as escolas

Fonte: Dos autores (2021).

Ao serem questionados sobre a adoção de algum planejamento de apoio para o atleta que apresenta baixo rendimento escolar, 70\% dos treinadores afirmam adotar alguma ação, tais como: "Dias e horário de treinos flexíveis para focar no rendimento escolar" (TREINADOR 3); "Procuro conversar com os pais e tentar alinhar o treinamento com a escola. Porém é muito difícil fazer esta 
O rendimento escolar e o esporte na vida de alunos/atletas

Deyvid Tenner de Souza Rizzo • Rogério Zaim-de-Melo • Alcides José Scaglia • Marcelo José Taques • Ana Paula Moreira de Sousa

conciliação" (TREINADOR 1); "Reduz em 30 minutos o treino para que possam estudar, assim tendo garantia que a estão fazendo" (TREINADOR 6). Já 30\% apontaram que "não temos isso nos treinos" (TREINADOR 9), ou que "são muitas demandas pra dar conta de tudo isso" (TREINADOR 10).

O próximo gráfico demonstra as percepções dos treinadores sobre o desempenho escolar dos atletas em geral na escola a partir de suas próprias experiências. Nesse sentido, indicaram que a maioria dos atletas:

Gráfico 2. Avaliação do desempenho escolar dos atletas

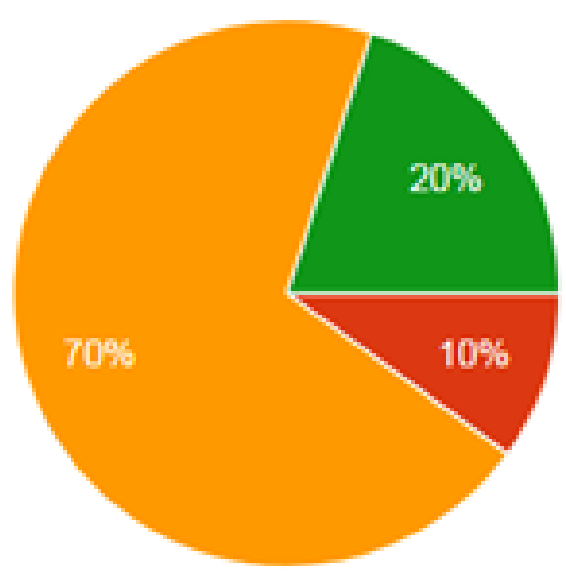

- tem fraco desempenho escolar

- tem medio desempenho escolar

tem bom desempenho escolar

- tem ótimo desempenho escolar

Fonte: Dos autores (2021).

No quadro a seguir, com diferentes perspectivas, três perguntas tentaram mensurar o grau da opinião dos treinadores numa escala de "1" a " 5 ", no qual " 1 " significa nunca, " 2 " raramente, " 3 " às vezes, "4" muitas vezes, "5" sempre. 
O rendimento escolar e o esporte na vida de alunos/atletas

Deyvid Tenner de Souza Rizzo • Rogério Zaim-de-Melo • Alcides José Scaglia • Marcelo José Taques • Ana Paula Moreira de Sousa

Quadro 1. Grau da opinião dos treinadores acerca da influência do esporte no desempenho escolar

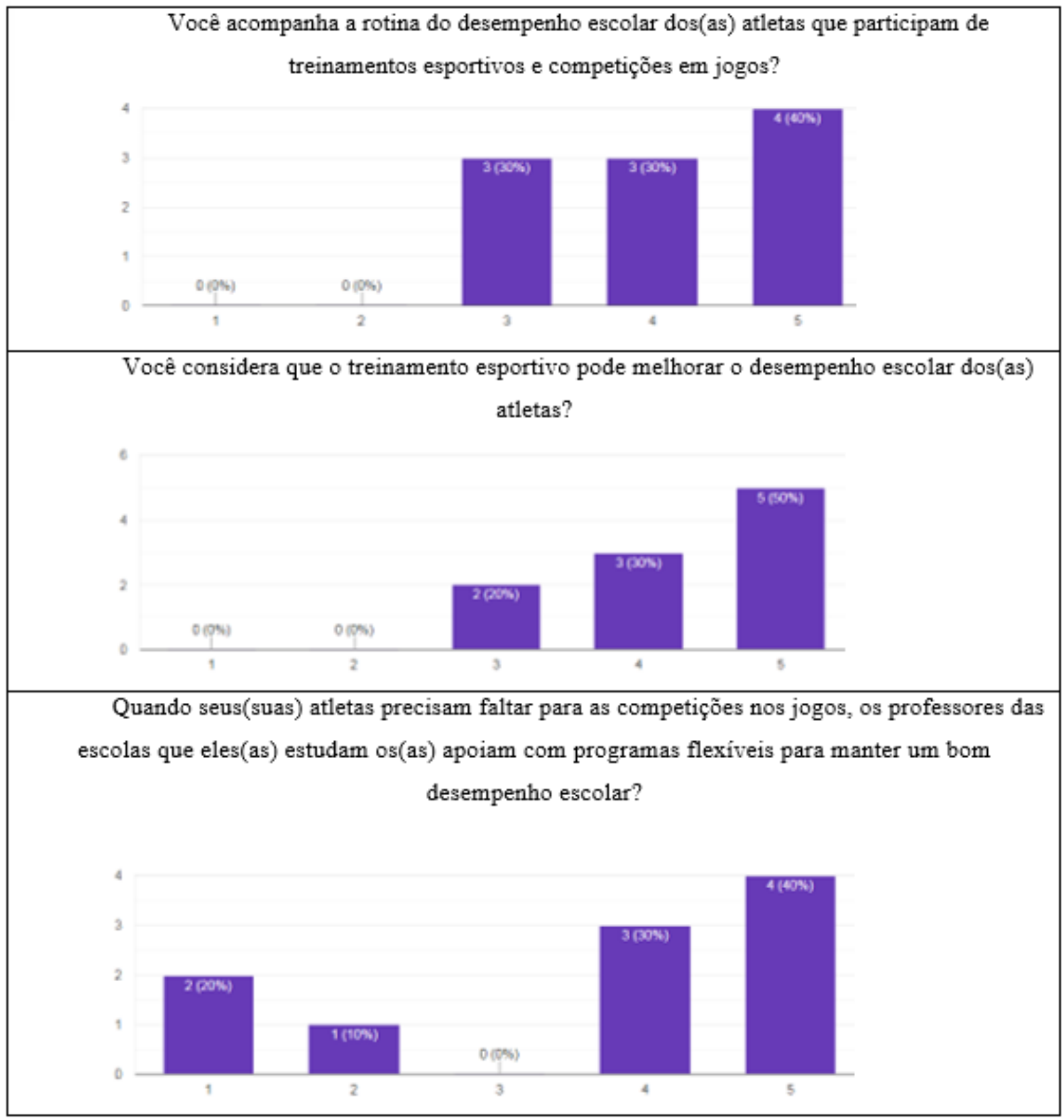

Fonte: Dos autores (2021).

As respostas da útima questão (aberta) (Quais são suas ações para com os atletas que apresentam baixo rendimento escolar?) foram inseridas separadamente no software Iramuteq, o que gerou uma "análise de similitude", possibilitando identificar as coocorrências entre as palavras e seu resultado traz indicações da cone- 
O rendimento escolar e o esporte na vida de alunos/atletas

Deyvid Tenner de Souza Rizzo • Rogério Zaim-de-Melo • Alcides José Scaglia • Marcelo José Taques • Ana Paula Moreira de Sousa

xidade entre os vocábulos, auxiliando na identificação da estrutura da representação (ver imagem 1).

Figura 1. Análise de similitudes de palavras presentes nas falas dos treinadores

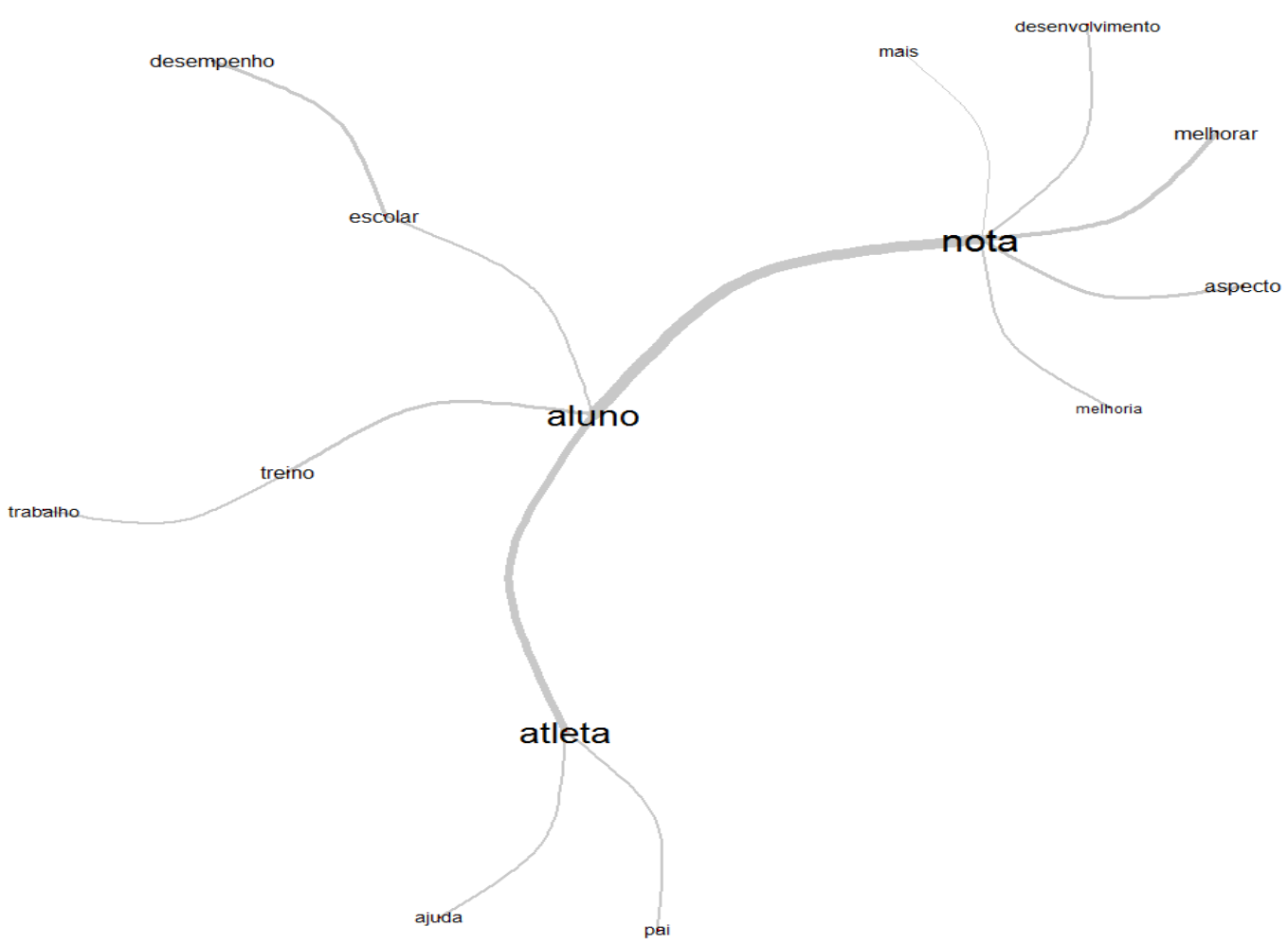

Fonte: Dos autores (2021).

A Análise de Similitudes dos depoimentos dos treinadores demonstra que as conexões entre as palavras formam dois blocos temáticos, são eles: "nota" e "aluno". Ao categorizar as palavras em classes com o software Iramuteq, pode-se visualizar aproximações e distanciamentos nos discursos dos treinadores, destacando 2 categorias divididas, que serão descritas aqui em duas classes.

A classe "nota" indica evidências de uma tentativa de os treinadores mensurarem o rendimento escolar de seus atletas como requisito para participação dos treinos. O Treinador 9 afirma que os atletas que apresentam baixo rendimento escolar "ficam 1 se- 
O rendimento escolar e o esporte na vida de alunos/atletas

Deyvid Tenner de Souza Rizzo • Rogério Zaim-de-Melo • Alcides José Scaglia • Marcelo José Taques • Ana Paula Moreira de Sousa

mana sem treino, depois precisam mostrar os cadernos em dia, conteúdo das provas e os trabalhos".

A classe "aluno" é composta por diversas palavras, contudo, a mais recorrente foi a palavra "atleta". Os depoimentos dos treinadores enfatizam a necessidade de o atleta ser um bom aluno, assim como descreve o Treinador 7: "Eu sempre incentivo meus atletas a "fecharem a notas" no terceiro bimestre, dizendo que as competições mais importantes estão justamente no último bimestre e que eles precisam estar "todos juntos para poder participar".

\section{Análise dos resultados}

Os resultados permitem afirmar que, em quase sua totalidade, o grupo de treinadores considera que o treinamento esportivo não atrapalha o desempenho escolar dos atletas, tendo em vista que os treinadores aqui investigados desenvolvem atividades esportivas caracterizadas pela alta competitividade das equipes e por eventos organizados conforme regras institucionalizadas.

Ainda que os atletas não sejam profissionais, pode-se dizer que eles buscam a excelência esportiva. E, nesse caso, “nas equipes esportivas o treinador desempenha a função de líder e procura influenciar os atletas para alcançarem seus objetivos" (RODRIGUES; SALDANHA, 2016, p. 2). Por isso, é importante que os treinadores adotem algum tipo planejamento de apoio para o atleta que apresenta baixo rendimento escolar, pois esse comportamento pode trazer impactos positivos para além do desempenho escolar dos atletas.

O fato de os treinadores indicarem que a maioria de seus atletas tem um bom desempenho escolar é um elemento-chave que pode resultar em sucesso no âmbito esportivo e oferecer elementos positivos transferíveis para toda a vida. E, no âmago do enredo esportivo, isso pode surgir de "implicações ou práticas diferentes entre os treinadores envolvidos no treinamento e desenvolvimento dos atletas" (VIEIRA et al., 2015, p. 6). 
Embora o acompanhamento do desempenho escolar dos atletas seja feito de diversas formas pelos treinadores, "o planejamento das práticas esportivas" (LUGUETTI et al., 2015) entre escolares sugere uma reflexão sobre a formação do treinador, o que aponta a necessidade de incorporar outros temas para essa discussão, com especificidades próprias da prática esportiva realizada em períodos de escolarização de alunos-atletas. Nesse viés, possibilitar um aprofundamento de conhecimentos e vivências que culminam e garantam ótimos níveis de desempenho escolar, sem perder a qualidade no desenvolvimento de uma prática esportiva, é dever dos treinadores e da escola.

A falta de apoio da escola, especialmente dos professores em geral, para as competições e jogos, é um elemento que os treinadores afirmaram contribuir para a queda do desempenho escolar. Nesse contexto, é necessário enfatizar a importância das implicações e comportamentos dos treinadores para a construção de um ambiente motivacional (BALAGUER et al., 2015), unidos a uma rotina de acompanhamento do desempenho escolar dos atletas que participam de treinamentos esportivos e competições em jogos.

Um pequeno grupo de treinadores disse que não adota nenhum planejamento de apoio para o atleta que apresenta baixo rendimento escolar ou pondera que o treinamento esportivo pode atrapalhar o desempenho escolar. Isso é preocupante, pois o planejamento pautado em orientações e trocas de experiências pode garantir a permanência com sucesso do aluno atleta dentro do contexto escolar concomitante à realização da prática esportiva, principalmente ao observar um "crescimento no número de escolas brasileiras que também oferecem modalidades esportivas como atividades extracurriculares no contraturno, denominadas práticas esportivas escolares, esporte escolar ou turmas de treinamento" (LUGUETTI et al., 2013, p. 1). A partir desses pressupostos, ressalta-se a necessidade da articulação de programas que incentivem a capacitação de treinadores, no intuito de prepará-los para essas novas demandas sociais no meio esportivo. 
Destarte, a influência do esporte no rendimento escolar de jovens atletas pode ser uma condição relacionada à capacidade do treinador de adquirir conhecimentos específicos que superem as adversidades encontradas para realização das práticas esportivas entre os alunos- atletas. A experiência como treinador é um importante indicativo de conhecimentos. A formação de um treinador é uma complexa combinação de aprendizagem formal, que ocorre num sistema institucionalizado, não formal, caracterizada como qualquer atividade sistemática organizada fora do sistema formal, como seminários, workshops e clínicas, e informal, que é um longo processo pelo qual o treinador adquire e acumula conhecimentos, habilidades, atitudes e percepções das experiências diárias (MARCON; GRAÇA; NASCIMENTO, 2010).

\section{Considerações finais}

Com este estudo, objetivamos analisar a influência do esporte no rendimento escolar de alunos-atletas participantes dos JOJUMS a partir da percepção de treinadores. Chama-nos atenção que uma pequena parcela da amostra de sujeitos acreditou que o desempenho pode ser prejudicado pelo desenvolvimento de práticas esportivas. Contudo, em geral, não foram encontrados indícios significantes de que o desempenho escolar é prejudicado pela rotina dos treinos e competições.

A partir da percepção dos treinadores, verificou-se que a falta de apoio dos professores das escolas com programas flexíveis pode dificultar o bom desempenho escolar dos alunos-atletas. Portanto, consideramos que um trabalho interdisciplinar entre treinadores, professores e gestores escolares pode favorecer 0 planejamento e execução de ações que promovam mudanças positivas para o desempenho escolar e para programas de treinamento esportivo em níveis de competição dos alunos atletas.

Advogamos que treinadores envolvidos no esporte com estudantes devem assumir a responsabilidade de desenvolverem as 
capacidades esportivas de seus atletas, conciliando a busca pelo melhor desempenho escolar aliado ao bem-estar físico, psicológico e social. A partir disso, portanto, esperamos que os dados ora levantados estimulem e subsidiem futuras discussões sobre a influência do esporte no rendimento escolar de alunos-atletas a partir da percepção de treinadores. Esta pesquisa se limitou a analisar a percepção de treinadores, estudos futuros poderão verificar os efeitos de variáveis pessoais dos treinadores (por exemplo, sexo, nível de experiência, tipo de modalidade, regionalidade etc.) e avançar nas discussões sobre suas percepções sobre o rendimento escolar de seus atletas.

\section{Referências}

ACHKAR, Ana Maria Nunes. Et al. Life Satisfaction and Academic Performance of Elementary School Students. Psico-USF, Campinas, v. 24, n. 2, p. 323-335, abr. 2019.

BALAGUER, Isabel. et al. Coaches as promoters of team cohesion. Cuadernos de Psicología del Deporte, v. 15, n. 1, p. 233-242, jan. 2015.

BRACHT, Valter. Esporte na escola e esporte de rendimento. Movimento (ESEF/UFRGS), Rio Grande do sul, v. 6, n. 12, p. 14-24, 23 out. 2001.

BREKKE, Idunn. Health and educational success in adolescents: a longitudinal study. BMC Public Health, v. 7, n. 15, 2015.

CAMARGO, Brigido Vizeu; JUSTO, Ana Maria. Tutorial para uso do software de análise textual IRAMUTEQ. Florianópolis: Laboratório de Psicologia Social da Comunicação e Cognição LACCOS da Universidade Federal de Santa Catarina., 2013.

CENTERS FOR DISEASE CONTROL AND PREVENTION. Centers for Disease Control and Prevention. Atlanta, GA:U.S. Department of Health and Human Services, , 2010. 
FORMIGA, Nilton Soares. O tipo de orientação cultural e sua influência sobre os indicadores do rendimento escolar. Revista Psicologia teoria e prática, São Paulo, v. 6, n. 1, p. 13-29, 2004. GAYA, Adroaldo. Sobre o Esporte para Crianças e Jovens. Movimento (ESEF/UFRGS), Rio Grande do Sul, v. 6, n. 13, p. 1-14, 2000.

LOVISOLO, Hugo. Mediação: esporte rendimento e esporte da escola. Movimento (ESEF/UFRGS), Rio Grande do Sul, v. 7, n. 15, p. 107-117, 4 dez. 2001.

LUGUETTI, Carla Nascimento. et al. Práticas esportivas escolares na cidade de Santos-SP: o ponto de vista dos professores/treinadores. Motriz: rev. educ. fis., São Paulo, v. 19, n. 1, p. 10-21, mar. 2013.

LUGUETTI, Carla Nascimento. et al. O planejamento das práticas esportivas escolares no ensino fundamental na cidade de Santos. Revista Brasileira de Ciências do Esporte, Brasília, v. 37, n. 4, p. 314-322, out. 2015.

MACHADO, João Cláudio. et al. Enhancing learning in the context of Street football: a case for Nonlinear Pedagogy. Physical Education and Sport Pedagogy, v. 1, p. 1-15, 2019.

MAHENDRA, Fénita Manuel; MARIN, Angela Helena. Ambiente familiar e rendimento escolar de adolescentes. Psic.: Teor. e Pesq. cidade, v.35, 2020.

MARCHESI, Álvaro; GIL, Carlos Hernández. Fracasso escolar: uma perspectiva multicultural. Porto Alegre: Artmed, 2004.

MARCON, Daniel; GRAÇA, Amândio Braga dos Santos; NASCIMENTO, Juarez Vieira do. Estruturantes da base de conhecimentos para o ensino de estudantes-professores de Educação Física. Motriz, São Paulo, v. 16, n. 3, p. 776-787, 2010.

MINAYO, Maria Cecília de Souza. 0 desafio do conhecimento: pesquisa qualitativa em saúde. 4. ed. São Paulo/Rio de Janeiro: HUCITEC/ABRASCO, 2004. 
NETA, Abília Ana Ana de Castro et al. O currículo cultural da Educação Física e os significados das práticas corporais: análise de uma prática pedagógica. Pensar a Prática, Goiânia, v. 23, 2020.

OLIVA, Maria Isabel Gandra. et al. Senso de coerência e fatores associados ao desempenho escolar de adolescentes. Ciência \& Saúde Coletiva, Manguinhos, v. 24, n. 8, p. 3057-3066, ago. 2019. OLIVEIRA, Vitor. Marinho. 0 esporte pode tudo. São Paulo: Cortez, 2010.

PACÍFICO, Ana Beatriz. et al. Comparison of physical fitness and quality of life between adolescents engaged in sports and those who are not. Revista Brasileira de Cineantropometria \& Desempenho Humano, Florianópolis, v. 20, n. 6, p. 544-554, dez. 2018.

PELEGRINI, Andreia et al. Aptidão física relacionada à saúde de escolares brasileiros: dados do projeto esporte Brasil. Revista Brasileira de Medicina do Esporte, São Paulo, v. 17, n. 2, p. 92-96, abr. 2011.

RATINAUD, Pierre.; MARCHAND, Pascal. Application de la méthode ALCESTE à de "gros" corpus et stabilité des "mondes lexicaux": analyse du "CableGate" avec IraMuTeQ. Journées internationales d'Analyse statistique des Données Textuelles., p. 835-844, 2012. RIZZO, Deyvid Tenner de Souza. Esporte para todos ou quase todos? considerações sobre a prática esportiva educacional. 1. ed. Ponta Porã-MS: EdFAMAG, 2017.

RODRIGUES, Vinicius de Matos; SALDANHA, Ana Alayde Werba. Liderança e satisfação no esporte escolar: teste da hipótese da congruência do modelo multidimensional de liderança. Psicologia: Ciência e Profissão, Brasília, v. 36, n. 3, p. 653-667, 2016.

SCAGLIA, Alcides José. et al. O ensino dos jogos esportivos coletivos: as competências essenciais e a lógica do jogo em meio ao processo de organizacional sistêmico. Movimento (ESEFID/ UFRGS), Rio Grande do Sul, v. 19, n. 4, p. 227-249, 23 ago. 2013. 
SERBIN, Lisa; STACK, Dale; KINGDON, Danielle. Academic success across the transition from primary to secondary schooling among lower-income adolescents: understanding the effects of family resources and gender.J Youth Adolesc, v. 42, n. 9, p. 1331-1347, 2013.

SIERRA-DÍAZ, Manuel Jacob. et al. Can we motivate students to practice physical activities and sports through models-based practice? A systematic review and meta-analysis of psychosocial factors related to physical education. Frontiers in Psychology, $v$. 10, n. 2115, 2019.

SILVA, Harrison Vinícius Amaral. et al. The effect of an initiation to struggles structured program on the physical capacities, visual attention and school performance in elementary school children. Revista Brasileira de Ciências do Esporte, Brasília, v. 41, n. 2, p. 176-182, jun. 2019.

SILVA, Paulo Rodrigo Pedroso da. et al. Doping survey in the youth school games in brazil. Revista Brasileira de Medicina do Esporte, São Paulo, v. 23, n. 6, p. 436-440, dez. 2017.

SILVA, Luciana Maria Fernandes; RUFINO, Luiz Gustavo Bonatto; DARIDO, Suraya Cristina. Capoeira e temas transversais: avaliação de um blog didático para as aulas de educação física. ETD - Educação Temática Digital, Campinas, v. 15, n. 1, p. 87-106, 2013.

TAFFAREL, Celi Nelza Zulke. Desporto Educacional: realidade e possibilidades das políticas governamentais e das práticas pedagógicas nas escolas públicas. Movimento (ESEF/UFRGS), Rio Grande do Sul, v. 6, n. 13, p. 15-35, 2000.

TEIXEIRA, Rafael Gambino. et al. Habilidade motora especializada: desenvolvimento motor nos esportes. EFDeportes.com - Revista Digital, n. 157, 2016.

TELFORD, Richard. et al. Physical Education, Obesity, and Academic Achievement: A 2-Year Longitudinal Investigation of Australian Elementary School Children. American Journal of Public Health, v. 20, n. 11, 2011. 
THOMAS, Jerry; NELSON, Jack; SILVERMAN, Stephen. Método de pesquisa em atividade física. 6. ed. Porto Alegre: Artmed, 2012. TORRES, Aline Lima. et al. As tecnologias da informação e comunicação e a educação física escolar: a realidade de professores da rede pública municipal de Fortaleza. ETD - Educação Temática Digital, Campinas, v. 18, n. 1, p. 198-214, 2016.

VAZ, Alexandre Fernandez. Técnica, Esporte, Rendimento. Movimento (ESEF/UFRGS), Rio Grande do Sul, v. 7, n. 14, p. 87-99, 30 nov. 2001.

José Luiz Lopes. et al. Impact of coach-athlete relationship on the collective efficacy of young volleyball players. Rev. bras. cineantropom. desempenho, Florianópolis, v. 17, n. 6, p. 650-660, dez. 2015.

VILELLA-CORTEZ, Glória Maria; FERREIRA, Heloisa Helena Marrara; BELLA, Geruza Perlato. Comparative study between school and motor performance in children aged 6 to 11 years according to teachers' perceptions. Fisioterapia em Movimento, Curitiba, v. 32, 2019.

WINDING, Trine. et al. Personal predictors of educational attainment after compulsory school: influence of measures of vulnerability, health, and school performance. Scand J Public Health, v. 41 , n. 1, p. 92-101, 2013.

WINDING, Trine; ANDERSEN, Johan Hviid. Socioeconomic differences in school dropout among young adults: the role of social relations. BMC Public Health, v. 15, 2015.

\section{Publisher}

Universidade Federal de Goiás. Faculdade de Educação Física e Dança. Publicação no Portal de Periódicos UFG. As ideias expressadas neste artigo são de responsabilidade de seus autores, não representando, necessariamente, a opinião dos editores ou da universidade. 